\title{
Lymphocyte to C-reactive protein ratio predicts long-term outcomes for patients with lower rectal cancer
}

\author{
Masaaki Nishi* (D), Mistuo Shimada, Takuya Tokunaga, Jun Higashijima, Kozo Yoshikawa, Hideya Kashihara, \\ Chie Takasu, Daichi Ishikawa, Yuma Wada, Shohei Eto and Toshiaki Yoshimoto
}

\begin{abstract}
Backgrounds: The lymphocyte to C-reactive protein (CRP) ratio (LCR) is an indicator of systemic inflammation and host-tumor cell interactions. The aim of this study was to investigate the prognostic significance of LCR in lower rectal cancer patients who received preoperative chemo-radiotherapy (CRT).

Methods: Forty-eight patients with lower rectal cancer who underwent CRT followed by curative surgery were enrolled in this study. Routine blood examinations were performed before and after CRT were used to calculate pre-CRT LCR and post-CRT LCR. The median LCR was used to stratify patients into low and high LCR groups for analysis. The correlation between pre- and post-CRT LCR and clinical outcomes was retrospectively investigated.

Results: The pre-CRT LCR was significantly higher than the post-CRT LCR (11,765 and 6780, respectively, $\mathrm{P}<0.05)$. The 5-year overall survival rate was significantly higher for patients with high post-CRT LCR compared with low post-CRT LCR (90.6\% and 65.5\%, respectively, P < 0.05). In univariate analysis, post-CRT LCR, post-CRT neutrophil to lymphocyte ratio, and fStage were significant prognostic factors for overall survival. In multivariate analysis, post-CRT $L C R$, but not other clinicopathological factors or prognostic indexes, was a significant prognostic factor for overall survival $(P<0.05)$.
\end{abstract}

Conclusions: Post-CRT LCR could be a prognostic biomarker for patients with lower rectal cancer.

Keywords: Rectal cancer, Chemoradiotherapy, Lymphocyte-CRP ratio

\section{Introduction}

Preoperative chemoradiotherapy (CRT) has become the standard treatment for patients with locally advanced lower rectal cancer (RC). CRT contributes to local control of disease progression and downstaging, reduces postoperative local recurrence, and favors long-term survival [1-3]. Systemic inflammation, immune-nutritional status, and host-tumor interactions are recognized as prognostic biomarkers for several types of malignancy [4-13]. Previous reports have demonstrated that various \footnotetext{
Tokushima 770-8503, Japan

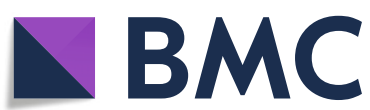

* Correspondence: nishi.masaaki@tokushima-u.ac.jp Department of Surgery, Tokushima University, 3-18-15 Kuramoto-cho,

(C) The Author(s). 2021 Open Access This article is licensed under a Creative Commons Attribution 4.0 International License, which permits use, sharing, adaptation, distribution and reproduction in any medium or format, as long as you give appropriate credit to the original author(s) and the source, provide a link to the Creative Commons licence, and indicate if changes were made. The images or other third party material in this article are included in the article's Creative Commons licence, unless indicated otherwise in a credit line to the material. If material is not included in the article's Creative Commons licence and your intended use is not permitted by statutory regulation or exceeds the permitted use, you will need to obtain permission directly from the copyright holder. To view a copy of this licence, visit http://creativecommons.org/licenses/by/4.0/ The Creative Commons Public Domain Dedication waiver (http://creativecommons.org/publicdomain/zero/1.0/) applies to the data made available in this article, unless otherwise stated in a credit line to the data. serum C-reactive protein $[\mathrm{CRP}])$, nutritional markers (total serum protein, serum albumin), and immune markers (neutrophil count, platelet count, and total lymphocyte count [TLC]), can be used to generate predictive indexes such as the lymphocyte to CRP ratio (LCR), neutrophil to lymphocyte ratio (NLR), prognostic nutritional index (PNI, based on serum albumin and TLC), CRP to albumin ratio, and Glasgow prognostic score (based on serum albumin and CRP) [4-13]. We previously reported that post-CRT NLR correlated with overall survival (OS) after surgery in patients with lower 
RC [9], highlighting the potential prognostic utility of such combination marker indexes.

Among the various prognostic scores investigated, preoperative LCR has been identified as an independent prognostic biomarker in patients with colorectal cancer (CRC) [10]. LCR is easily measurable from routine laboratory data and is a reflection of the status of the host anti-tumor immune and systemic inflammatory responses [10]. To date, however, only a few reports have considered the prognostic significance of LCR, including the utility of pre- and post-CRT LCR, in patients with cancers of the gastrointestinal tract $[10,14-16]$. Therefore, the aim of the present study was to investigate the prognostic significance of pre-and post-CRT LCR in patients with lower RC who underwent preoperative CRT.

\section{Materials and methods}

\section{Patients and study design}

A total of 48 patients with lower RC who underwent CRT followed by curative resection at Tokushima University Hospital between 2004 and 2012 were included in this retrospective study. The protocol was approved by the Ethics Committee of Tokushima University (approval no. 3215-1) and was conducted according to the provisions of the Declaration of Helsinki. All patients provided informed consent for the use of their data.

\section{Patient characteristics}

Table 1 shows the clinicopathological characteristics of 48 patients. Clinical data were obtained from medical records and included demographic information, laboratory data, tumor properties, staging, and treatment modalities. Routine laboratory tests were performed on the first day of CRT and within 1 week after the final day of CRT.

\section{Preoperative CRT}

The preoperative CRT treatment schedule was described previously [9, 17]. In brief, all 48 patients received 5fluorouracil (5-FU)-based chemotherapy: 29 received tegafur-gimeracil-oteracil (S-1), 8 received tegafur-uracil (UFT), and 11 received 5-FU alone intravenously. S-1 $\left(80 \mathrm{mg} / \mathrm{m}^{2}\right)$ and UFT $\left(300 \mathrm{mg} / \mathrm{m}^{2}\right)$ were administered orally on days $1-5$ of each week for 5 weeks, and intravenous 5 -FU $\left(600 \mathrm{mg} / \mathrm{m}^{2}\right)$ was administered on days 1 , 8,15 , and 26. All patients received a total of 40 Gy radiotherapy (RT), which was delivered at 2.0 Gy per day on days $1-5$ for 4 weeks. Patients underwent radical surgery within 6 to 8 weeks of the end of CRT. The inclusion criteria for CRT were (i) Eastern Cooperative Oncology Group performance status 0-2, (ii) white blood cell count $\geq 4000 / \mu \mathrm{L}$, (iii) platelet count $\geq 100$, $000 / \mu \mathrm{L}$, (iv) serum total bilirubin $<1.5 \mathrm{mg} / \mathrm{dL}$, (v) serum creatinine $<1.5 \mathrm{mg} / \mathrm{dL}$, and (vi) normal heart function.
Table 1 Clinicopathological characteristics of all patients $(n=48)$

\begin{tabular}{|c|c|}
\hline Characteristic & $\begin{array}{l}\text { All patients } \\
(\mathrm{n}=48)\end{array}$ \\
\hline Age (years) & $66 \pm 11$ \\
\hline Gender (male/female) & $32 / 16$ \\
\hline $\mathrm{WBC}(/ \mu \mathrm{L})$ & $6747 \pm 2794$ \\
\hline $\operatorname{TLC}(/ \mu \mathrm{L})$ & $1627 \pm 601$ \\
\hline Alb (mg/dL) & $3.8 \pm 0.5$ \\
\hline CRP (mg/dL) & $0.65 \pm 1.83$ \\
\hline \multicolumn{2}{|l|}{ Tumor characteristic } \\
\hline Differentiation (tub1/tub2/other) & $27 / 19 / 2$ \\
\hline $\operatorname{CEA}(</ \geq 5 \mathrm{ng} / \mathrm{mL})$ & $34 / 14$ \\
\hline CA19-9 $(</ \geq 37 \mathrm{IU} / \mathrm{mL})$ & $40 / 8$ \\
\hline Pre-CRT stage (I/II/II) & $3 / 11 / 28$ \\
\hline \multicolumn{2}{|l|}{ Treatment } \\
\hline Chemotherapy (S-1/UFT/5-FU) & 29/8/11 \\
\hline Surgery (LAR/ISR/APR/local) & $18 / 11 / 17 / 2$ \\
\hline
\end{tabular}

WBC white blood cell, $T L C$ total lymphocyte count, $A / b$ albumin, CRP C-reactive protein, CEA carcinoembryonic antigen, tub1 well-differentiated tubular adenocarcinoma, tub2 moderately differentiated tubular adenocarcinoma, $S-1$ tegafur-gimeracil-oteracil, UFT tegafur-uracil, 5-FU 5-fluorouracil, CRT chemoradiotherapy, LAR low anterior resection, ISR intersphincteric resection, $A P R$ abdominoperineal resection

Eighteen patients underwent low anterior resection, 10 patients underwent intersphincteric resection, $11 \mathrm{pa}-$ tients underwent abdominoperineal resection, and $2 \mathrm{pa}-$ tients underwent trans-anal local resection. Pathological responses were evaluated by pathologists according to the Japanese Classification of Colorectal Carcinoma. Patients were followed up postoperatively for at least 5 years. Recurrence of primary RC was evaluated by tumor marker levels and computed tomography.

\section{LCR calculation}

LCR was calculated as the ratio of TLC (per $\mu \mathrm{L}$ ) to serum CRP (mg/dL) (10). The median LCR (11,765 preCRT and 6780 post-CRT) was used as the cutoff for stratification of patients into low and high pre-CRT LCR and post-CRT LCR groups. Clinicopathological parameters, OS, and disease-free survival (DFS) were evaluated among the four groups.

\section{Statistical analysis}

All statistical analyses were performed using JMP 8.0.1 software (SAS Institute, Cary, NC, USA). Clinical variables were analyzed with Chi-square and Wilcoxson's tests. OS and DFS were analyzed by the Kaplan-Meier method. Multivariate analysis was performed using a logistic regression model. Statistical significance was defined as $\mathrm{P}<0.05$. 


\section{Results}

Changes in TLC, serum CRP, and LCR following CRT are shown in Fig. 1. TLC was significantly lower postCRT compared with pre-CRT $(810 / \mu \mathrm{L}$ and $1662 / \mu \mathrm{L}$, respectively, $\mathrm{P}<0.05$; Fig. $1 \mathrm{~A}$ ), whereas serum CRP did not change significantly $(0.14 \mathrm{mg} / \mathrm{dL}$ and $0.12 \mathrm{mg} / \mathrm{dl}$, respectively, Fig. 1B). Consequently, the post-CRT LCR was also significantly lower than the pre-CRT LCR, with median values of 6780 and 11,765, respectively (Fig. 1C, $\mathrm{P}<0.05)$. LCR was increased in 13 patients and decreased in 35 patients after CRT (Fig. 1C).

Associations between pre-CRT and post-CRT LCR and clinicopathological parameters in patients assigned to low and high LCR groups are shown in Tables 2 and 3. A significant correlation between pre-CRT LCR and clinicopathological characteristic was found only for CRP (Table 2), whereas CRP, TLC, and pre-CRT LCR were significantly correlated with post-CRT LCR (Table 3). The prognostic significance of pre-CRT LCR and post-CRT LCR is shown in Fig. 2. Patients in the
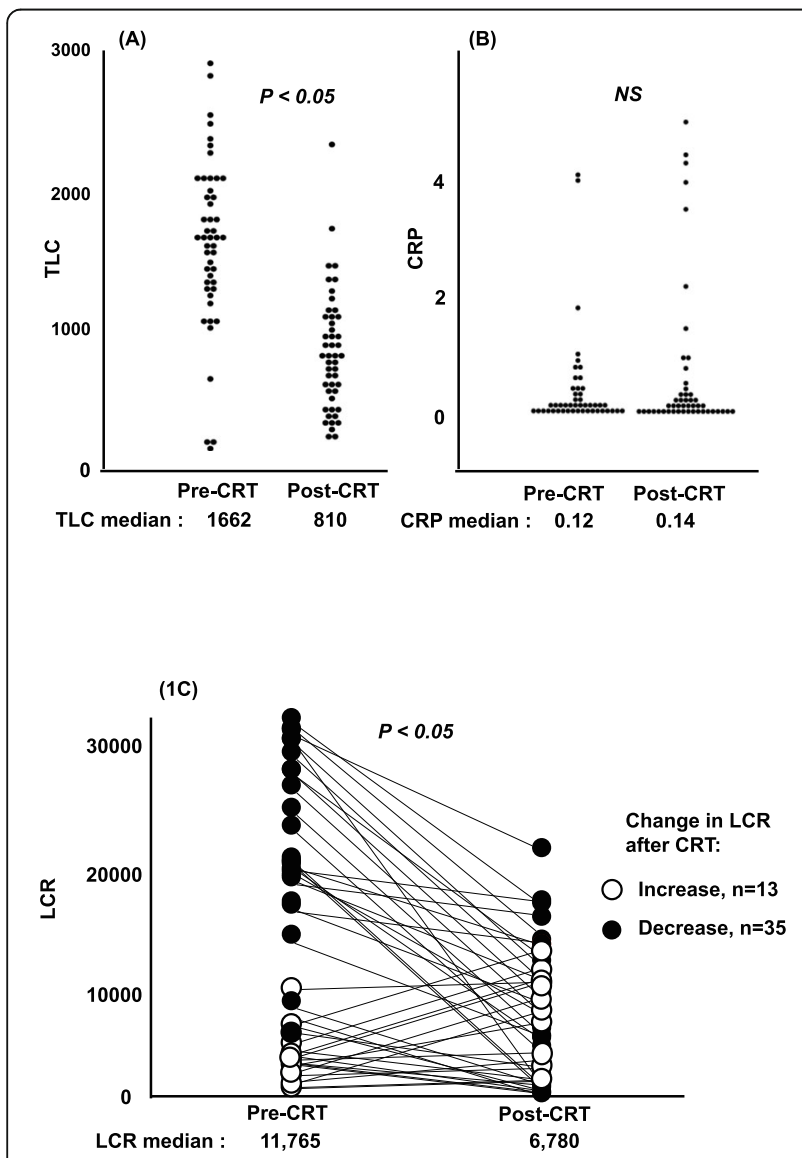

Fig. 1 TLC, CRP and CRP change before and after CRT. A-C Changes in TLC (A), CRP (B), and LCR (C) values between pre-CRT and postCRT for the 48 patients with rectal cancer. TLC, total lymphocyte count; CRP, C-reactive protein; LCR, lymphocyte-CRP ratio; CRT, chemo-radiotherapy
Table 2 Clinicopathological characteristics of patients stratified by pre-CRT LCR

\begin{tabular}{|c|c|c|c|}
\hline Characteristic & $\begin{array}{l}\text { LCR low } \\
(n=24)\end{array}$ & $\begin{array}{l}\text { LCR high } \\
(\mathrm{n}=24)\end{array}$ & $P$ value \\
\hline Age (years) & $66 \pm 13$ & $65 \pm 10$ & 0.45 \\
\hline Gender (male/female) & $16 / 8$ & $16 / 8$ & 1.00 \\
\hline WBC $(/ \mu \mathrm{L})$ & 7266 & 6299 & 0.13 \\
\hline $\mathrm{TLC}(/ \mu \mathrm{L})$ & $1451 \pm 640$ & $1803 \pm 502$ & 0.07 \\
\hline Alb (mg/dL) & $3.8 \pm 0.5$ & $3.9 \pm 0.5$ & 0.58 \\
\hline $\mathrm{CRP}(\mathrm{mg} / \mathrm{dL})$ & $1.23 \pm 2.47$ & $0.07 \pm 0.02$ & $<0.05$ \\
\hline \multicolumn{4}{|l|}{ Tumor characteristic } \\
\hline Differentiation (tub1/tub2/other) & $13 / 7 / 4$ & $16 / 4 / 4$ & 0.53 \\
\hline $\mathrm{CEA}(</ \geq 5 \mathrm{ng} / \mathrm{mL})$ & $16 / 8$ & $18 / 6$ & 1.00 \\
\hline CA19-9 (</ $\geq 37 \mathrm{IU} / \mathrm{mL})$ & $20 / 4$ & $20 / 4$ & 0.09 \\
\hline Pre-CRT stage (I/II/III) & $1 / 3 / 16$ & $2 / 8 / 12$ & 0.17 \\
\hline \multicolumn{4}{|l|}{ Treatment } \\
\hline Chemotherapy (S-1/UFT/5FU) & $13 / 7 / 4$ & $16 / 4 / 4$ & 0.57 \\
\hline Surgery (LAR/ISR/APR/local) & $7 / 4 / 13 / 0$ & $11 / 6 / 5 / 2$ & 0.07 \\
\hline Pathological response (grade $2 />2$ ) & $17 / 7$ & $15 / 9$ & 0.53 \\
\hline
\end{tabular}

Patients were stratified using the median LCR. WBC white blood cell, TLC total lymphocyte count, Alb albumin, CRP C-reactive protein, CEA carcinoembryonic antigen, $L C R$ lymphocyte-CRP ratio, tub1 well-differentiated tubular adenocarcinoma, tub2 moderately differentiated tubular adenocarcinoma, $S-1$ tegafur-gimeracil-oteracil, UFT tegafur-uracil, 5-FU 5-fluorouracil, CRT chemoradiotherapy, LAR low anterior resection, ISR intersphincteric resection, $A P R$ abdominoperineal resection

low pre-CRT LCR group had poorer 5-year OS compared with the high pre-CRT LCR group, albeit not significantly $(70.3 \%$ and $80.1 \%$, respectively, $\mathrm{P}=0.14$; Fig. 2A). In contrast, patients in the low post-CRT LCR group had significantly poorer 5-year OS than the high post-CRT LCR group $(65.5 \%$ and $90.6 \%$, respectively, P $<0.05$; Fig. 2C). Notably, there were no significant differences in DFS between patients with high and low preCRT LCR (Fig. 2B) or post-CRT LCR (Fig. 2D).

Univariate analysis revealed that fStage, post-CRT NLR, and post-CRT LCR were significant prognostic factors for OS. Multivariate analysis demonstrated that CA19-9 level and post-CRT LCR were independent prognostic factors for OS (Table 4). The sites of RC recurrence were not significantly different between the high and low post-CRT LCR groups, whereas a high post-CRT LCR was significantly associated with surgery as a curative treatment (Table $5, \mathrm{P}<0.05$ ).

\section{Discussion}

In the current study, we retrospectively analyzed the significance of LCR as a prognostic marker for patients with lower RC who received preoperative CRT. LCR is of great potential interest as a prognostic marker because it reflects the systemic inflammatory and immune responses and can be readily calculated from routinely 
Table 3 Clinicopathological characteristics of patients stratified by post-CRT LCR

\begin{tabular}{|c|c|c|c|}
\hline Characteristic & $\begin{array}{l}\text { LCR low } \\
(\mathrm{n}=24)\end{array}$ & $\begin{array}{l}\text { LCR high } \\
(\mathrm{n}=24)\end{array}$ & $P$ value \\
\hline Age (years) & $67 \pm 13$ & $64 \pm 9$ & 0.36 \\
\hline Gender (male/female) & $17 / 7$ & $15 / 9$ & 0.54 \\
\hline WBC $(/ \mu \mathrm{L})$ & $5391 \pm 1652$ & $4441 \pm 1127$ & 0.06 \\
\hline $\mathrm{TLC}(/ \mu \mathrm{L})$ & $730 \pm 460$ & $971 \pm 347$ & $<0.05$ \\
\hline Alb (mg/dL) & $3.4 \pm 0.5$ & $3.9 \pm 0.4$ & 0.91 \\
\hline CRP $(\mathrm{mg} / \mathrm{dL})$ & $1.10 \pm 1.60$ & $0.26 \pm 0.71$ & $<0.05$ \\
\hline Pre-CRT LCR & $9006 \pm 9368$ & $23322 \pm 13945$ & $<0.05$ \\
\hline \multicolumn{4}{|l|}{ Tumor characteristic } \\
\hline Differentiation (tub1/tub2/other) & $9 / 14 / 1$ & 10/13/1 & 0.41 \\
\hline $\mathrm{CEA}(</ \geq 5 \mathrm{ng} / \mathrm{mL})$ & $18 / 6$ & $16 / 8$ & 0.53 \\
\hline CA19-9 (</ $\geq 37 \mathrm{IU} / \mathrm{mL})$ & $20 / 4$ & $20 / 4$ & 1.00 \\
\hline Pre-CRT stage (I/I/III) & $1 / 3 / 15$ & $2 / 8 / 13$ & 0.20 \\
\hline \multicolumn{4}{|l|}{ Treatment } \\
\hline Chemotherapy (S-1/UFT/5FU) & $12 / 9 / 3$ & $17 / 2 / 5$ & 0.05 \\
\hline Surgery (LAR/ISR/APR/local) & $9 / 3 / 11 / 1$ & $9 / 7 / 7 / 1$ & 0.47 \\
\hline Pathological response (grade $2 / \geq 2$ ) & $16 / 8$ & $16 / 8$ & 1.00 \\
\hline
\end{tabular}

WBC white blood cell, TLC total lymphocyte count, Alb albumin, CRP C-reactive protein, CEA carcinoembryonic antigen, $L C R$ lymphocyte-CRP ratio, tub1 welldifferentiated tubular adenocarcinoma, tub2 moderately differentiated tubular adenocarcinoma, S-1 tegafur-gimeracil-oteracil, UFT tegafur-uracil, 5-FU 5-

fluorouracil, CRT chemo-radiotherapy, LAR low anterior resection, ISR intersphincteric resection, APR abdominoperineal resection
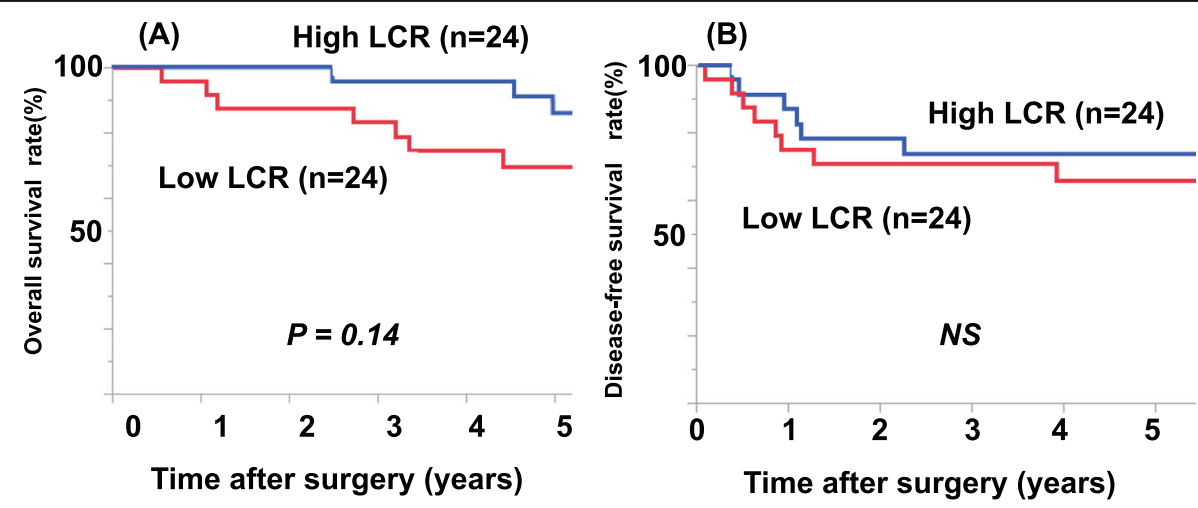

(C)

High LCR (n=24)

(D)
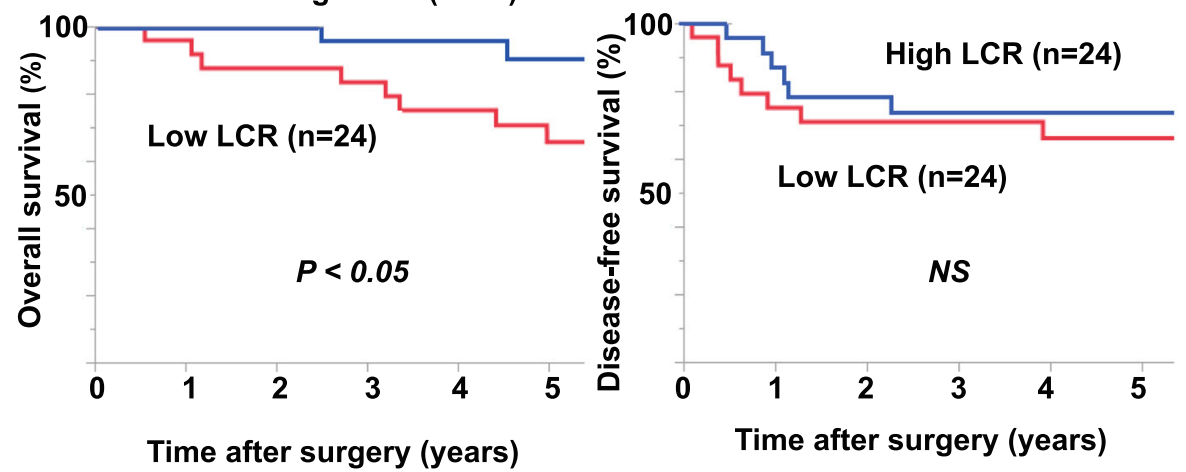

Fig. 2 Prognostic impact of preoperative lymphocyte-CRP ratio (LCR) in RC patients. A-D Overall survival (A, C) and disease-free survival (B, D) of patients stratified by pre-CRT LCR groups $(\mathbf{A}, \mathbf{B})$ and post-CRT LCR groups (C, D). Patients were stratified using the median LCR. CRT, chemoradiotherapy; LCR, lymphocyte-CRP ratio 
Table 4 Univariate and multivariate analysis of associations between clinicopathological characteristics and overall survival

\begin{tabular}{|c|c|c|c|c|}
\hline \multirow[t]{2}{*}{ Characteristic } & \multicolumn{2}{|c|}{ Univariate analysis } & \multicolumn{2}{|c|}{ Multivariate analysis } \\
\hline & 5-year OS (\%) & $P$ value & Hazard ratio & $P$ value \\
\hline Age $(</ \geq 70$ years $)$ & $70.1 / 82.0$ & 0.20 & 0.99 & 0.99 \\
\hline Gender (male/female) & $80.4 / 72.7$ & 0.56 & 1.22 & 0.81 \\
\hline WBC $(</ \geq 9000 / \mu \mathrm{L})$ & $74.8 / 100$ & 0.31 & 5.13 & 0.39 \\
\hline $\operatorname{TLC}(</ \geq 1500 / \mu \mathrm{L})$ & $72.2 / 81.8$ & 0.44 & 0.72 & 0.83 \\
\hline $\operatorname{Alb}(</ \geq 4 \mathrm{mg} / \mathrm{dL})$ & $71.5 / 84.6$ & 0.90 & 0.67 & 0.68 \\
\hline $\operatorname{CRP}(</ \geq 0.5 \mathrm{mg} / \mathrm{dL})$ & $77.3 / 80.0$ & 0.77 & 0.10 & 0.14 \\
\hline \multicolumn{5}{|l|}{ Tumor characteristic } \\
\hline Differentiation (tub1/tub2) & $84.2 / 70.2$ & 0.09 & 3.72 & 0.31 \\
\hline CEA $(</ \geq 5 \mathrm{ng} / \mathrm{mL})$ & 74.9/84.6 & 0.68 & 0.63 & 0.64 \\
\hline CA19-9 (</ $\geq 37 \mathrm{IU} / \mathrm{mL})$ & $84.0 / 42.9$ & 0.07 & 19.8 & $<0.05$ \\
\hline Pathological response (grade $2 />2$ ) & $73.2 / 87.5$ & 0.07 & 0.27 & 0.27 \\
\hline fStage $(I / I / I I)$ & $86.4 / 61.9$ & $<0.05$ & 3.27 & 0.30 \\
\hline \multicolumn{5}{|l|}{ Immune factors } \\
\hline Pre-CRT PNI (low/high) & $78.2 / 78.0$ & 0.99 & 0.72 & 0.85 \\
\hline Post-CRT PNI (low/high) & $67.1 / 90.1$ & 0.19 & 4.24 & 0.29 \\
\hline Pre-CRT NLR (low/high) & $83.3 / 73.2$ & 0.38 & 0.80 & 0.85 \\
\hline Post-CRT NLR (low/high) & $95.6 / 61.5$ & $<0.05$ & 1.15 & 0.92 \\
\hline Pre-CRT LCR (low/high) & $70.3 / 80.1$ & 0.14 & 0.30 & 0.34 \\
\hline Post-CRT LCR (low/high) & $65.5 / 90.6$ & $<0.05$ & 0.06 & $<0.05$ \\
\hline
\end{tabular}

For low/high categories, patients were stratified using the median LCR. WBC white blood cell, TLC total lymphocyte count, Alb albumin, CRP C-reactive protein, CEA carcinoembryonic antigen, tub1 well-differentiated tubular adenocarcinoma, tub2 moderately differentiated tubular adenocarcinoma, $S$-1 tegafur-gimeracil-oteracil, UFT tegafur-uracil, 5-FU 5-fluorouracil, CRT chemo-radiotherapy, LAR low anterior resection, ISR intersphincteric resection, $A P R$ abdominoperineal resection, TLC total lymphocyte count, $L C R$ lymphocyte-CRP ratio, NLR neutrophil-lymphocyte ratio, $P N I$ prognostic nutritional index

Table 5 Associations between post-CRT LCR and recurrence site or treatment modality

\begin{tabular}{|c|c|c|c|}
\hline \multirow[t]{2}{*}{ Characteristic } & \multirow{2}{*}{$\begin{array}{l}\text { LCR low } \\
\text { (n = 24) } \\
N\end{array}$} & \multirow{2}{*}{$\begin{array}{l}\text { LCR high } \\
(n=24) \\
N\end{array}$} & \multirow[t]{2}{*}{$\begin{array}{l}P \\
\text { value }\end{array}$} \\
\hline & & & \\
\hline Recurrence & 8 & 8 & NS \\
\hline Site of recurrence & & & NS \\
\hline Local & 1 & 8 & \\
\hline Pelvic LNs & 2 & 2 & \\
\hline Liver & 3 & 1 & \\
\hline Lung & 4 & 3 & \\
\hline Distant LNs & 1 & 2 & \\
\hline \multicolumn{4}{|l|}{ Treatment } \\
\hline Surgery & 1 & 6 & $<0.05$ \\
\hline Liver resection & 0 & 3 & \\
\hline Lung resection & 1 & 1 & \\
\hline Local resection & 0 & 2 & \\
\hline Chemotherapy & 7 & 2 & \\
\hline BSC & 0 & 0 & \\
\hline
\end{tabular}

Patients were stratified using the median LCR. LN lymph node, BSC best supportive care, LCR lymphocyte-CRP ratio, NS not significant collected laboratory data. We identified LCR as a reliable biomarker of prognosis in our patient cohort, with low post-CRT LCR being significantly correlated with poor prognosis in both univariate and multivariate analysis. We also evaluated the potential prognostic significance of PNI and NLR, which are composed of combinations of neutrophil, lymphocyte, and platelet counts, and serum albumin and CRP levels, in univariate and multivariate analysis; however, neither of these scores was an independent prognostic factor for OS in our cohort.

A paradigm shift in cancer treatment has resulted in interactions between the tumor and immune system becoming a major therapeutic target $[18,19]$. In particular, multiple lymphocyte subsets play crucial roles in antitumor immunity, and many immune checkpoint inhibitors targeting $\mathrm{T}$ lymphocytes are currently in use for the treatment of various cancers. Accordingly, cancer patients with high TLC generally have a better prognosis $[20,21]$. Within the tumor microenvironment, tumor cells may also interact with a variety of other cells, such as myeloid-derived suppressor cells, tumor-associated macrophages, mast cells, dendritic cells, and cancerassociated fibroblasts in the tumor stroma. Interactions between tumor cells and host cells stimulate not only 
tumor growth but also angiogenesis and metastasis [2224]. Tumor-infiltrating lymphocytes (TILs) are key markers of the anti-tumor immune response, and positive associations have been described between the abundance of TILs and prognosis of patients with various cancers [25-29]. Kitayama et al. reported that the number of peripheral blood lymphocytes correlated significantly with the rate of complete response to RT of patients with advanced RC, and they considered that lymphocyte-mediated responses may therefore play a pivotal role in the effects of RT [29]. Furthermore, Lee et al. suggested that peripheral lymphocyte counts correlated with TILs in breast cancer and that TLC might serve as a surrogate marker of TILs [30].

Local and systemic inflammatory responses are thought to promote cancer through several mechanisms [31, 32], including promotion of tumor cell growth and angiogenesis, and inhibition of DNA damage and apoptosis via inflammatory cytokines and chemokines [33, 34]. Moreover, several inflammatory markers may act as predictors of the therapeutic response [35-37]. For example, CRP is a prognostic indicator for several types of solid tumors, including CRC [35-37].

Okugawa et al. first identified LCR as a promising biomarker for CRC in their analysis of several candidate prognostic biomarkers that included neutrophil count, TLC, platelet count, albumin, and CRP [10]. The significance of LCR has also been demonstrated in patients with esophageal, gastric, and rectal cancer who received CRT [14-16].

Our results in the current study show that high postCRT LCR may be a predictive marker of better prognosis for patients with RC undergoing CRT followed by curative surgery. The high post-CRT LCR in our cohort was largely a reflection of post-CRT maintenance of TLC with a small, but insignificant, increase in CRP level, and it might therefore be indicative of strong antitumor immunity and a mild pro-inflammatory effect on the microenvironment. Interestingly, although elevated post-CRT LCR predicted favorable OS, there was no significant association between post-CRT LCR and DFS. A high post-CRT LCR was most common among patients who received curative surgery, whereas a low post-CRT LCR was more common among patients who received chemotherapy as a palliative treatment. Moreover, the time to treatment failure (recurrence) tended to be longer for high post-CRT LCR group than the low postCRT LCR group (data not shown), which may be due to a stronger overall anti-tumor immune response in patients with high post-CRT LCR. Accordingly, patients with high post-CRT LCR might be considered for adjuvant treatment to prevent recurrence.

There are some limitations to our study. This was a single-center retrospective study and the results may not extrapolate to other environments. In addition, the sample size was small. Multicenter studies with larger cohorts will be needed to overcome these limitations, validate the results of this study, and identify the optimal cutoff value for the LCR for further studies of its prognostic value.

In conclusion, the findings of the present study suggest that the LCR could be an important predictive biomarker for the prognosis of patients with lower $\mathrm{RC}$ who undergo CRT followed by curative surgery.

\section{Abbreviations}

RC: Rectal cancer; CRT: Chemoradiotherapy; RT: Radiotherapy; CRP: C-reactive protein; TLC: Total lymphocyte count; LCR: Lymphocyte-CRP ratio;

NLR: Neutrophil to lymphocyte ratio; PNI: Prognostic nutritional index

\section{Acknowledgements}

We thank Anne M. O'Rourke, PhD, from Edanz Group (https://en-authorservices.edanz.com/ac) for editing a draft of this manuscript.

\section{Authors' contributions}

Masaaki Nishi: conceptualization, methodology, validation, formal analysis investigation, writing. Mistuo Shimada: supervision. Takuya Tokunaga: formal analysis, writing. Jun Higashijima: project administration. Kozo Yoshikawa: validation. Hideya Kashihara: methodology. Chie Takasu: methodology. Daichi Ishikawa: methodology. Yuma Wada: investigation. Shohei Eto: investigation. Toshiaki Yoshimoto: investigation. All authors read and approved the final manuscript

\section{Funding}

No specific funding is exist in this study.

Availability of data and materials

Data not available due to ethical restriction.

\section{Declarations}

\section{Ethics approval consent to participate}

The study protocol was approved by the Ethics Committee of Tokushima University (approval no.3215-1) and conformed to the provisions of the Declaration of Helsinki. All patients provided informed consent to participate in this study for the use of their personal data.

\section{Competing interests}

The authors declare that they have no competing interests.

Received: 19 April 2021 Accepted: 25 June 2021

Published online: 06 July 2021

\section{References}

1. Dattani M, Heald RJ, Goussous G, Broadhurst J, São Julião GP, Habr-Gama A et al. Oncological and survival outcomes in watch and wait patients with a clinical complete response after neoadjuvant chemoradiotherapy for rectal cancer: a systematic review and pooled analysis. Ann Surg. 2018;268(6):95567. https://doi.org/10.1097/SLA.0000000000002761.

2. Cercek A, Roxburgh CSD, Strombom P, Smith JJ, Temple LKF, Nash GM, et al. Adoption of total neoadjuvant therapy for locally advanced rectal cancer. JAMA Oncol. 2018;4(6):e180071. https://doi.org/10.1001/jamaoncol.2 018.0071.

3. Sauer R, Becker H, Hohenberger W, Rödel C, Wittekind C, Fietkau R, et al. Preoperative versus postoperative chemoradiotherapy for rectal cancer. $\mathrm{N}$ Engl J Med. 2004;351(17):1731-40. https://doi.org/10.1056/NEJMoa040694.

4. Jansson H, Cornillet M, Björkström NK, Sturesson C, Sparrelid E. Prognostic value of preoperative inflammatory markers in resectable biliary tract cancer - validation and comparison of the Glasgow Prognostic Score and Modified Glasgow Prognostic Score in a Western cohort. Eur J Surg Oncol. 2020;46(5): 804-10. https://doi.org/10.1016/j.ejso.2019.12.008. 
5. Liu Z, Shi H, Chen L. Prognostic role of pre-treatment C-reactive protein/ albumin ratio in esophageal cancer: a meta-analysis. BMC Cancer. 2019; 19(1):1161. https://doi.org/10.1186/s12885-019-6373-y.

6. Cheng $H$, Long $F$, Jaiswar $M$, Yang L, Wang $C$, Zhou Z. Prognostic role of the neutrophil-to-lymphocyte ratio in pancreatic cancer: a meta-analysis. Sci Rep. 2015:5(1):11026. https://doi.org/10.1038/srep11026.

7. Yang L, Xia L, Wang Y, Hong S, Chen H, Liang S, et al. Low prognostic nutritional index (PNI) predicts unfavorable distant metastasis-free survival in nasopharyngeal carcinoma: a propensity score-matched analysis. Plos One. 2016;11(7):e0158853. https://doi.org/10.1371/journal.pone.0158853.

8. Hirashima K, Watanabe $M$, Shigaki H, Imamura $Y$, Ida S, Iwatsuki M, et al. Prognostic significance of the modified Glasgow prognostic score in elderly patients with gastric cancer. J Gastroenterol. 2014;49(6):1040-466. https:// doi.org/10.1007/s00535-013-0855-5

9. Ishikawa D, Nishi M, Takasu C, Kashihara H, Tokunaga T, Higashijima J, et al. The role of neutrophil-to-lymphocyte ratio on the effect of CRT for patients With rectal cancer. In Vivo. 2020;34(2):863-8. https://doi.org/10.21873/ invivo.11850.

10. Okugawa $Y$, Toiyama $Y$, Yamamoto A, Shigemori T, Ide S, Kitajima T, et al. Lymphocyte-C-reactive protein ratio as promising new marker for predicting surgical and oncological outcomes in colorectal cancer. Ann Surg. 2020;272(2):342-51. https://doi.org/10.1097/SLA.0000000000003239.

11. Panagiotis $P$, Simona $D$, Svilen M, Tsvetelina $P$, Ahmed F, Abdrabou M, et al. Blood cell count indexes as predictors of anastomotic leakage in elective colorectal surgery: a multicenter study on 1432 patients. World J Surg Oncol. 2020;18(1):89. https://doi.org/10.1186/s12957-020-01856-1.

12. Liao CK, Yu YL, Lin YC, Hsu YJ, Chern YJ, Chiang JM, et al. Prognostic value of the C-reactive protein to albumin ratio in colorectal cancer: an updated systematic review and meta-analysis. World J Surg Oncol. 2021;19(1):139. https://doi.org/10.1186/s12957-021-02253-y.

13. Sufana HA, Ailín CR, Priscilla P, Paul TC, Geoff GA, Ann EB, et al. Preoperative $\mathrm{C}$-reactive protein and other inflammatory markers as predictors of postoperative complications in patients with colorectal neoplasia. World J Surg Oncol. 2021;19(1):74. https://doi.org/10.1186/s12957-021-02142-4.

14. Yamamoto A, Toiyama Y, Okugawa $Y$, Ichikawa T, Imaoka H, Yasuda H, et al. Clinical implications of the preoperative lymphocyte $\mathrm{C}$-reactive protein ratio in esophageal cancer patients. Surg Today. 2020;51(5):745-55. https://doi. org/10.1007/s00595-020-02166-5.

15. Okugawa $Y$, Toiyama $Y$, Fujikawa $H$, Ide S, Yamamoto A, Omura $Y$, et al. Prognostic potential of lymphocyte-C-reactive protein ratio in patients with rectal cancer receiving preoperative chemoradiotherapy. J Gastrointest Surg. 2020;25(2):492-502. https://doi.org/10.1007/s11605-019-04495-4

16. Okugawa Y, Toiyama Y, Yamamoto A, Shigemori T, Ichikawa T, Yin C, et al. Lymphocyte-to-C-reactive protein ratio and score are clinically feasible nutrition-inflammation markers of outcome in patients with gastric cancer Clin Nutr. 2020;39(4):1209-17. https://doi.org/10.1016/j.clnu.2019.05.009.

17. Hotchi M, Shimada M, Kurita N, Iwata T, Sato H, Morimoto S, et al. Shortterm results of laparoscopic surgery after preoperative chemoradiation for clinically staged T3 and T4 rectal cancer. Asian J Endosc Surg. 2012;5(4):15763. https://doi.org/10.1111/j.1758-5910.2012.00148.x.

18. Kang YK, Boku N, Satoh T, Ryu MH, Chao Y, Kato K, et al. Nivolumab in patients with advanced gastric or gastro-oesophageal junction cancer refractory to, or intolerant of, at least two previous chemotherapy regimens (ONO-4538-12, ATTRACTION-2): a randomised, double-blind, placebocontrolled, phase 3 trial. Lancet. 2017;390(10111):2461-71. https://doi.org/1 0.1016/S0140-6736(17)31827-5.

19. Wolchok JD, Chiarion-Sileni V, Gonzalez R, Rutkowski P, Grob JJ, Cowey CL, et al. Overall survival with combined nivolumab and ipilimumab in advanced melanoma. N Engl J Med. 2017;377(14):1345-56. https://doi.org/1 0.1056/NEJMoa1709684.

20. Ahn S, Park JS, Jang J, Ahn KJ, Hong YK, Yang SH, et al. The association between total lymphocyte count after concomitant chemoradiation and overall survival in patients with newly diagnosed glioblastoma. J Clin Neurosci. 2020;71:21-5. https://doi.org/10.1016/j.jocn.2019.11.017.

21. Hongen $X$, Guangxian Y, Minjun Z, Tao S, Haibo Z, Jia Y, et al. Association of pre-surgery to pre-radiotherapy lymphocyte counts ratio with disease-free survival in rectal cancer patients receiving neoadjuvant concurrent chemoradiotherapy. World J Surg Oncol. 2019;17(1):199. https://doi.org/1 0.1186/s12957-019-1747-9

22. Eissmann MF, Dijkstra C, Jarnicki A, Phesse T, Brunnberg J, Poh AR, et al. IL33-mediated mast cell activation promotes gastric cancer through macrophage mobilization. Nat Commun. 2019;10(1):2735. https://doi.org/1 0.1038/s41467-019-10676-1.

23. De Palma M, Biziato D, Petrova TV. Microenvironmental regulation of tumour angiogenesis. Nat Rev Cancer. 2017;17(8):457-74. https://doi.org/1 $0.1038 /$ nrc. 2017.51

24. Joyce JA, Fearon DT. T cell exclusion, immune privilege, and the tumor microenvironment. Science. 2015;348(6230):74-80. https://doi.org/10.1126/ science.aaa6204.

25. Savas P, Salgado R, Denkert C, Sotiriou C, Darcy PK, Smyth MJ, et al. Clinical relevance of host immunity in breast cancer: from TILs to the clinic. Nat Rev Clin Oncol. 2015;13:228-41.

26. Stanton SE, Disis ML. Clinical significance of tumor-infiltrating lymphocytes in breast cancer. J Immunother Cancer. 2016;4(1):59. https://doi.org/10.1186/ s40425-016-0165-6.

27. Kong JC, Guerra GR, Pham T, Mitchell C, Lynch AC, Warrier SK, et al. Prognostic impact of tumor-infiltrating lymphocytes in primary and metastatic colorectal cancer: a systematic review and meta-analysis. Dis Colon Rectum. 2019;62(4):498-508. https://doi.org/10.1097/DCR. 0000000000001332

28. Kitayama J, Yasuda K, Kawai K, Sunami E, Nagawa H. Circulating lymphocyte is an important determinant of the effectiveness of preoperative radiotherapy in advanced rectal cancer. BMC Cancer. 2011;11(1):64. https:// doi.org/10.1186/1471-2407-11-64

29. Yamei Z, Xiaoxu G, Jiawei H, Yi C, Zhanhuai W, Jian W, et al. The prognostic value of tumor-infiltrating lymphocytes in colorectal cancer differs by anatomical subsite: a systematic review and meta-analysis. World J Surg Oncol. 2019;17(1):85. https://doi.org/10.1186/s12957-019-1621-9.

30. Lee $Y Y$, Choi $\mathrm{CH}$, Sung CO, Do IG, Hub SJ, Kim HJ, et al. Clinical significance of changes in peripheral lymphocyte count after surgery in early cervical cancer. Gynecol Oncol. 2012;127(1):107-13. https://doi.org/10.1016/j.ygyno.2 012.05.039.

31. Mantovani A, Allavena P, Sica A, Balkwill F. Cancer-related inflammation. Nature. 2008:454(7203):436-44. https://doi.org/10.1038/nature07205.

32. Coussens LM, Werb Z. Inflammation and cancer. Nature. 2002;420(6917): 860-7. https://doi.org/10.1038/nature01322.

33. Tan TP, Arekapudi A, Metha J, Prasad A, Venkatraghavan L. Neutrophillymphocyte ratio as predictor of mortality and morbidity in cardiovascular surgery: a systematic review. ANZ J Surg. 2015;85(6):414-9. https://doi.org/1 0.1111 /ans.13036

34. Zahorec R. Ratio of neutrophil to lymphocyte counts--rapid and simple parameter of systemic inflammation and stress in critically ill. Bratisl Lek Listy. 2001;102(1):5-14

35. Roxburgh CS, Salmond JM, Horgan PG, Oien KA, McMillan DC. Comparison of the prognostic value of inflammation-based pathologic and biochemical criteria in patients undergoing potentially curative resection for colorectal cancer. Ann Surg. 2009;249(5):788-93. https://doi.org/10.1097/SLA.0b013e31 $81 \mathrm{a} 3 \mathrm{e} 738$.

36. Leitch EF, Chakrabarti M, Crozier JE, McKee RF, Anderson JH, Horgan PG, et al. Comparison of the prognostic value of selected markers of the systemic inflammatory response in patients with colorectal cancer. $\mathrm{Br}$ J Cancer. 2007;97(9):1266-70. https://doi.org/10.1038/sj.bjc.6604027.

37. McMillan DC. Systemic inflammation, nutritional status and survival in patients with cancer. Curr Opin Clin Nutr Metab Care. 2009;12(3):223-6. https://doi.org/10.1097/MCO.0b013e32832a7902.

\section{Publisher's Note}

Springer Nature remains neutral with regard to jurisdictional claims in published maps and institutional affiliations. 